\title{
Comparison of Four Methods of Treating Ectopic Pregnancy: A Retrospective Cohort Study
}

\author{
Vergleich von 4 Methoden zur Behandlung der ektopen \\ Schwangerschaft: eine retrospektive Kohortenstudie
}

(우(1) (오 $\ominus$

Authors

Zeynep Ozturk Inal, Hasan Ali Inal

Affiliation

Konya Education and Research Hospital, Department

of Gynecology, Konya, Turkey

Key words

ectopic pregnancy, human chorionic gonadotropin, methotrexate, single dose, multiple dose, gynecology, infertility

Schlüsselwörter

ektope Schwangerschaft, humanes Choriongonadotropin, Methotrexat, Einzeldosis, mehrfache Dosen, Gynäkologie, Infertilität

received 23.9.2017

revised 29.10.2017

accepted 1.11 .2017

Bibliography

DOI https://doi.org/10.1055/s-0043-122151

Geburtsh Frauenheilk 2018; 78: 70-77 @ Georg Thieme

Verlag KG Stuttgart · New York | ISSN 0016-5751

Correspondence

Dr. Zeynep Ozturk Inal, M.D.

Konya Education and Research Hospital

Yeni Meram Cad., 42090 Meram Yeni Yol Konya, Turkey

zeynephafiza@gmail.com

\section{ABSTRACT}

Objective To compare the results of expectant management, single and multidose methotrexate (MTX) and surgical management of ectopic pregnancy (EP).

Materials and Methods In this retrospective cohort study, the original files of 233 patients who were treated for EP between May 2009 and December 2016 were analyzed. The patients were assigned to the following groups based on the applied treatment methods: Group 1, expectant management $(n=24)$, Group 2, single-dose MTX $(n=144)$, Group 3, multiple-dose MTX $(n=25)$, and Group 4, surgical intervention $(n=40)$. The following parameters were recorded and as- sessed: sociodemographic characteristics, pelvic ultrasonography findings (gestational sac, ectopic mass appearance, positive fetal cardiac activity), serum beta-human chorionic gonadotropin ( $\beta$-hCG) levels on Day 0 , Day 4 , and Day 7 , and surgical procedures in women that underwent surgical interventions.

Results The sociodemographic characteristics were similar in all four groups. The percentage of ectopic mass and positive fetal cardiac activity was greater and the diameter of the mass was larger in Group 4 than in the other groups. The $\beta$-hCG values on Day 0 , Day 4, and Day 7 were statistically different between the groups $(p<0.001)$. The cutoff value for the $\beta$-hCG change for EP resolution was $18 \%$ between Day 0 and Day 4 $(A \cup C=0.726, p<0.001)$ and $15 \%$ between Day 4 and Day 7 ( $A \cup C=0.874, p<0.001)$. The probability of the requirement for an additional dose of MTX was $0.78(95 \% \mathrm{Cl} 0.71-0.87$; $\mathrm{p}<0.001$ ) times lower in patients who had a $>18 \%$ decrease in $\beta$-hCG levels from Day 0 to Day 4 in comparison to those who had a decrease $<18 \%$ from Day 0 to Day 4 . The probability of the requirement for an additional dose of MTX was 1.64 $(95 \% \mathrm{Cl} 1.25-2.16 ; \mathrm{p}<0.001)$ times greater in patients whose reduction in $\beta$-hCG levels from Day 4 to Day 7 was $<15 \%$ in comparison to those who had $>15 \%$ reduction from Day 4 to Day 7.

Conclusions Additional dose requirements for patients with EP may be predicted early in the changes in $\beta$-hCG levels between Day 0 and Day 4. Further prospective studies are required to elucidate this issue.

\section{ZUSAMMENFASSUNG}

Ziel Ziel dieser Studie war es, 4 Methoden zur Behandlung einer ektopen Schwangerschaft (ES) miteinander zu vergleichen: das aktive Beobachten und Warten, die Behandlung mit Methotrexat (MTX), entweder als einmalige Gabe oder in mehrfachen Dosen, und der operative Eingriff.

Material und Methoden In dieser retrospektiven Kohortenstudie wurden die originalen Patientenakten von 233 Patientinnen ausgewertet, die zwischen Mai 2009 und Dezember 2016 wegen einer ES behandelt wurden. Je nach Behandlung wurden die Patientinnen in eine der folgenden Gruppen ein- 
geteilt: Gruppe 1 (aktives Beobachten und Warten; $n=24$ ), Gruppe 2 (einmalige Gabe von MTX; $n=144$ ), Gruppe 3 (mehrfache Gabe von MTX; $n=25$ ) und Gruppe 4 (operativer Eingriff; $n=40$ ). Die folgenden Kenngrößen wurden erfasst und ausgewertet: soziodemografische Merkmale, Ergebnisse der Beckensonografie (Fruchtsack, Erscheinungsbild der extrauterinen Masse, fetale Herztätigkeit), Serumspiegel von beta-humanem Choriongonadotropin ( $\beta$-hCG) am Tag 0 sowie am 4. und 7. Tag, und Art des operativen Eingriffs bei denjenigen Frauen, die sich einem operativen Eingriff unterzogen.

Ergebnisse Die soziodemografischen Merkmale waren in allen 4 Gruppen ähnlich. In der Gruppe 4 waren die Prozentsätze der ektopen Masse und der fetalen Herztätigkeit höher verglichen mit den anderen 3 Gruppen. Die $\beta$-hCG-Werte der Gruppen am Tage 0, am 4. Tag und am 7. Tag unterschieden sich statistisch signifikant $(p<0,001)$. Der Cut-off-Wert für $\beta$-hCG-Veränderungen, die auf eine Beendigung der ES hinwiesen, betrug $18 \%$ zwischen dem Tag 0 und dem 4. Tag ( $A \cup C=0,726, p<0,001)$ und $15 \%$ zwischen dem 4 . und dem
7. Tag ( $A \cup C=0,874, p<0,001)$. Die Wahrscheinlichkeit, dass eine weitere Dosis MTX benötigt wurde, war 0,78-mal (95\%KI 0,71-0,87; $p<0,001)$ niedriger bei Patientinnen, bei denen ein Rückgang von > 18\% der $\beta$-hCG-Werte zwischen dem Tag 0 und dem 4. Tag gemessen wurde, verglichen mit den Patientinnen, bei denen ein Rückgang von $<18 \%$ zwischen dem Tag 0 und dem 4. Tag verzeichnet wurde. Die Wahrscheinlichkeit, dass eine weitere Dosis MTX benötigt wurde, war 1,64mal (95\%-KI 1,25-2,16; $p<0,001)$ höher bei Patientinnen, bei denen ein Rückgang der $\beta$-hCG-Werte zwischen dem 4. und dem 7 . Tag von $<15 \%$ verzeichnet wurde, verglichen mit den Frauen, bei denen der Rückgang zwischen dem 4. und dem 7. Tag $>15 \%$ betrug.

Schlussfolgerungen Veränderungen der $\beta$-hCG-Werte zwischen dem Tag 0 und dem 4. Tag bei Patientinnen mit ES könnten ein frühzeitiger Hinweis auf einen zusätzlichen Bedarf an MTX-Gaben sein. Weitere prospektive Studien werden zur Klärung dieser Frage benötigt.

\section{Introduction}

Ectopic pregnancy (EP), defined as the implantation of a fertilized ovum outside of the endometrial cavity, accounts for approximately $1.3-2 \%$ of all pregnancies, and it is the most important cause of morbidity and mortality in the first trimester [1,2]. While several mechanisms have been proposed in the etiopathogenesis of EP, the main reasons for it are the partial obstruction of and defective ciliar movements in fallopian tubes [3].

It is important to remember that the risk factors of EP include a history of pelvic inflammatory disease, intrauterine device use (especially with progesterone), advanced maternal age, smoking, a history of tubal surgery, and a history of infertility, endometriosis and assisted reproductive technology therapy; it is important to note that risk factors can be undetected in more than half of all EP cases $[4,5]$. Pelvic or abdominal pain, vaginal bleeding, and amenorrhea are the most common symptoms in EP, which most often occurs in the fallopian tubes [3,6].

Due to the widespread use of sensitive quantitative beta-human chorionic gonadotropin ( $\beta$-hCG) assays and high-resolution ultrasonography (USG) in recent years, the possibility of early diagnosis in EP has increased, and a mortality rate decrease of up to $90 \%$ is possible with early intervention $[7,8]$. Nevertheless, the relative mortality risk is 10 times greater with EP than with vaginal birth, and it is 50 times greater than with a legal abortion [9]. Today, the goal of EP treatment is not only to save a mother's life; it should also aim to preserve fertility and reduce the cost of infertility treatment [10].

Based on the clinical situation of each patient, three basic approaches are used to treat and manage EP: expectant management, medical treatment and surgical treatment. Patients who are hemodynamically stable, suitable for long-term follow-up, have a small ectopic mass and no rupture findings (blood or coagulum) on transvaginal USG are candidates for expectant management, and they can be followed using serial serum $\beta$-hCG mea- surement $(8,10)$. Immediate surgical intervention should be considered for patients that are hemodynamically unstable and have acute abdominal findings of ruptured EP [11].

Medical treatment is the logical and cost-effective choice for unruptured EP, and the most commonly used and preferred agent in the world is methotrexate (MTX), which was first used in 1982 and which is a folic acid antagonist preventing purin-pyrimidine synthesis [12]. The two most common MTX treatment protocols are a single-dose regimen and a multiple-dose regimen, and the literature has reported success rates of 88 and $92.7 \%$, respectively. Previous studies have found that there was no difference in success rates between a single dose of MTX and multiple-dose MTX treatment $[4,13-16]$. Adverse effects, such as stomatitis, conjunctivitis, gastritis, enteritis, dermatitis, pneumonitis, alopecia, elevated liver enzymes, and bone marrow suppression, are rarely seen because the doses of MTX used in EP treatment are lower than the doses used to treat malignancies [4].

The single-dose regimen is preferred because it is low in cost, only requires a single injection, requires fewer hospital visits, does not require the use of folinic acid to rescue the treatment, and $50 \mathrm{mg} / \mathrm{m}^{2}$ of MTX can be administered intramuscularly on the day of diagnosis $[4,14]$. In the literature, a $>15 \%$ decrease in the level of $\beta$-hCG between Day 0 and Day 4 is considered to be a successful treatment $[13,14]$, and a > 15\% $\beta$-hCG decrease between Day 4 and Day 7 is generally acceptable [17].

In this present study, we aimed to compare the results of expectant management, single and multidose methotrexate and surgical management of EP cases between May 2009 and December 2016 in our clinic. 


\section{Materials and Method}

\section{Study design and population}

This retrospective cohort study was performed on women diagnosed with EP between May 1, 2009 and December 31, 2016 at the Gynecology Department of Konya Education and Research Hospital (a tertiary referral center), in Konya, Turkey. This study was approved by the institution's local ethics committee, and all the women provided written informed consent before undergoing treatment. Data on the EP treatment were collected from the patients' files and the hospital medical records, and were analyzed retrospectively. Sociodemographic characteristics included age, body mass index (BMI), clinical presentation, the use of contraceptive methods, a history of EP, a history of previous abdominal or pelvic surgery, a history of infertility treatment, smoking, gravidity, parity, miscarriage, gestational age, pelvic USC findings (gestational sac, ectopic mass appearance, positive fetal cardiac activity), serum $\beta$-hCG levels on Day 0 , Day 4 , and Day 7 , and a history of surgical procedures and hospital stays for women who underwent surgical interventions.

\section{Diagnosis and treatment protocol}

At our clinic, the diagnosis of EP was performed via persistent increase in $\beta$-hCG levels without the presence of intrauterine pregnancy or not showing the villi histopathologically in an endometrial biopsy. Patients that were hemodynamically stable and had a $>15 \%$ decrease in their daily $\beta$-hCG measurement were treated using expectant management, and spontaneous resorption of EP was expected. Patients who were hemodynamically unstable, had signs of intra-abdominal bleeding, desired elective surgery, were breastfeeding a baby, or who had peptic ulcer, renal, hepatic, pulmonary, hematological, or immunological diseases underwent surgery. Patients that were hemodynamically stable and had an abnormal serum $\beta$-hCG increase $(<50 \%$ increase over two consecutive days or whose levels had plateaued) were given MTX. For the single-dose protocol, after calculating the patient's body surface area, $50 \mathrm{mg} / \mathrm{m}^{2}$ MTX was administered intramuscularly and the serum $\beta$-hCG levels were measured on Day 0 , Day 4 , and Day 7 . If the $\beta$-hCG value measured on the seventh day decreased by $>15 \%$ in comparison to the $\beta$-hCG value measured on the fourth day, serial $\beta$-hCG measurements were performed until the $\beta$-hCG level was $<15 \mathrm{mIU} / \mathrm{L}$. If the decrease in $\beta$-hCG levels was $<15 \%$ between Day 4 and Day 7, a second dose of MTX was administered. Similarly, for the single-dose regimen, it was expected that the $\beta$-hCG level measured on the seventh day would decrease by $>15 \%$ from the $\beta$-hCG level measured on the fourth day. If that did not occur, a third and final dose of MTX was administered. After receiving three doses of MTX, if the decrease in the $\beta$-hCG level was not $>15 \%$ between Day 4 and Day 7 , surgical intervention was required.

\section{Statistical analysis}

Statistical analyses were performed using SPSS 15.0 for Windows (SPSS, Chicago, IL, USA). The Shapiro-Wilk test for normality was used to determine if the continuous variables had normal or abnormal distributions, while one-way analysis of variance (ANOVA) and paired-sample t-tests were used for the normally distributed continuous variables. The Kruskal-Wallis test was used to analyze the abnormally distributed continuous variables. When the Kruskal-Wallis test indicated statistically significant differences, the causes of those differences were determined using a Bonferroniadjusted Mann-Whitney $U$ test. The nominal variables were analyzed using either Pearson's chi-squared test or Fisher's exact test, when applicable. The continuous variables were presented as the mean \pm standard deviation (SD), and the categorical variables were presented as the number of cases and the percentage. Logistic regression analysis was used to identify the factors that required the use of additional doses of MTX. A receiver operating characteristic (ROC) analysis was used to determine the threshold values for changes in the $\beta$-hCG levels between Day 0 and Day 4 and Day 4 and Day 7 for an additional MTX dose. Statistical significance was set at $p<0.05$.

\section{Results}

\section{Demographic data}

A total of 233 diagnosed cases of EP were reviewed. According to our clinical protocol, 24 of the 233 patients were treated using expectant management (Group 1), 144 were treated with a single dose of MTX (Group 2), 25 were treated with a multiple dose of MTX (Group 3), and the remaining 40 patients underwent surgical intervention (Group 4).

The sociodemographic characteristics and USG findings of the patients with EP are presented in $>$ Table 1. The patients in all four groups did not differ significantly in terms of age, BMI, the main complaint on admission, contraceptive method use, history of EP, previous abdominal or pelvic surgery, history of infertility treatment, smoking, gravidity, parity and miscarriage. Gestational age was lower in Group 1 than in the other groups ( $p=0.007)$. The percentage of ectopic mass appearance and positive fetal cardiac activity measured using transvaginal USG was greater in Group 4 than in the other groups $(p<0.001)$. While the diameter of the ectopic mass was smaller in Group 1 than in the other groups, it was larger in Group $4(p<0.001)$.

\section{Laboratory outcomes}

A comparison of the $\beta$-hCG concentrations on Day 0 , Day 4 , and Day 7 between the groups is shown in - Table 2 . A statistically significant difference between the groups was observed $(p<0.001)$. The changes in the $\beta$-hCG values in the groups from Day 0 to Day 4 and from Day 4 to Day 7 after administration of MTX are presented in $\bullet$ Table 3 . A statistically significant difference between the groups was observed $(p<0.001)$.

In the ROC analysis ( $\triangleright$ Fig. 1 ), the cut-off value for changes in the $\beta$-hCG level was $18 \%$ between Day 0 and Day 4 ( $A \cup C=0.726$, $p<0.001)$; for Day 4 and Day 7 the cut-off value was $15 \%$ (AUC $=0.874, p<0.001$ ) for an additional MTX dose. The logistic regression analysis results showed that the probability of the requirement for an additional dose of methotrexate was 0.78 (95\% $\mathrm{Cl} 0.71-0.87 ; \mathrm{p}<0.001)$ times lower in patients who had $\mathrm{a}>18 \%$ decrease in $\beta$-hCG levels from Day 0 to Day 4 in comparison to those who had a decrease $<18 \%$ in those levels from Day 0 to 
- Table 1 Comparison of the sociodemographic characteristics and USG findings in patients with ectopic pregnancy.

\begin{tabular}{|c|c|c|c|c|c|}
\hline & $\begin{array}{l}\text { Group } 1 \\
\text { Expectant } \\
\text { management } \\
(\mathrm{n}=\mathbf{2 4 )}\end{array}$ & $\begin{array}{l}\text { Group } 2 \\
\text { Single dose } \\
\text { methotrexate } \\
(n=144)\end{array}$ & $\begin{array}{l}\text { Group } 3 \\
\text { Multiple dose } \\
\text { methotrexate } \\
(n=25)\end{array}$ & $\begin{array}{l}\text { Group } 4 \\
\text { Surgical } \\
\text { intervention } \\
(n=40)\end{array}$ & p-value \\
\hline Age (years) & $29.88 \pm 4.94$ & $31.64 \pm 4.97$ & $31.76 \pm 4.38$ & $31.10 \pm 4.40$ & 0.387 \\
\hline $\operatorname{BMI}\left(\mathrm{kg} / \mathrm{m}^{2}\right)$ & $23.28 \pm 1.91$ & $23.72 \pm 1.96$ & $23.96 \pm 2.19$ & $24.35 \pm 2.16$ & 0.176 \\
\hline Clinical presentation (\%) & & & & & 0.486 \\
\hline - Pain & $4(16.7)$ & $44(30.6)$ & $6(24.0)$ & $12(30.0)$ & \\
\hline - Vaginal bleeding & $2(8.3)$ & $36(25.0)$ & $6(24.0)$ & $11(27.5)$ & \\
\hline - Pain + vaginal bleeding & $4(16.7)$ & $29(20.1)$ & $5(20.0)$ & $8(20.0)$ & \\
\hline - Amenorrhea & $3(12.5)$ & $7(4.9)$ & $2(8.0)$ & $1(2.5)$ & \\
\hline - Pain + amenorrhea & $6(25.0)$ & $15(10.4)$ & $4(16.0)$ & $4(10.0)$ & \\
\hline - Vaginal bleeding + amenorrhea & $5(20.8)$ & $13(9.0)$ & $2(8.0)$ & $4(10.0)$ & \\
\hline Contraception (\%) & & & & & 0.115 \\
\hline - Negative & $16(66.7)$ & $97(67.4)$ & $10(40.0)$ & $17(42.5)$ & \\
\hline - Coitus interruptus & $2(8.3)$ & $15(10.4)$ & $3(12.0)$ & $5(12.5)$ & \\
\hline - Condom & $1(4.2)$ & $6(4.2)$ & $2(8.0)$ & $3(7.5)$ & \\
\hline - Bilateral tubal ligation & $1(4.2)$ & $4(2.8)$ & $4(16.0)$ & $4(10.0)$ & \\
\hline - Intrauterine device & $4(16.7)$ & $22(15.3)$ & $6(24.0)$ & $11(27.5)$ & \\
\hline History of ectopic pregnancy (\%) & $3(12.5)$ & $16(11.1)$ & $3(12.0)$ & $9(22.5)$ & 0.310 \\
\hline Previous intra-abdominal or pelvic surgery (\%) & $1(4.2)$ & $8(5.6)$ & $3(12.0)$ & $6(15.0)$ & 0.173 \\
\hline History of infertility treatment (\%) & $2(8.3)$ & $16(11.1)$ & $4(12.0)$ & $9(22.5)$ & 0.240 \\
\hline Smoking (\%) & $4(16.7)$ & $24(16.8)$ & $6(24.0)$ & $12(30.0)$ & 0.267 \\
\hline Gravidity & $2.08 \pm 1.65$ & $2.51 \pm 1.33$ & $2.80 \pm 1.25$ & $2.85 \pm 1.64$ & 0.115 \\
\hline Parity & $1.42 \pm 0.80$ & $1.87 \pm 0.94$ & $1.72 \pm 1.24$ & $2.10 \pm 1.25$ & 0.063 \\
\hline Miscarriage & $0.67 \pm 0.53$ & $0.64 \pm 0.54$ & $1.08 \pm 0.75$ & $0.88 \pm 0.58$ & 0.056 \\
\hline Gestational age (day) & $49.58 \pm 4.79^{1,2,3}$ & $53.63 \pm 9.14^{1}$ & $55.96 \pm 7.64^{2}$ & $56.30 \pm 4.43^{3}$ & $0.007^{*}$ \\
\hline Findings on USG (\%) & & & & & $<0.001^{*}$ \\
\hline - Gestational sac & $8(33.3)$ & $55(38.2)$ & $12(48.0)$ & $7(17.5)$ & \\
\hline - Ectopic mass appearance & $16(66)$. & $87(60.4)$ & $11(44.0)$ & $24(60.0)$ & \\
\hline - Positive fetal cardiac activity & $0(0)$ & $2(1.4)$ & $2(8.0)$ & $9(22.5)$ & \\
\hline Diameter of ectopic mass (mm) & $18.04 \pm 4.90^{1,2,3}$ & $22.60 \pm 6.91^{1,5}$ & $23.80 \pm 6.48^{2,6}$ & $30.25 \pm 3.12^{3,5,6}$ & $<0.001^{*}$ \\
\hline $\begin{array}{l}\text { BMI: body mass index; USG: ultrasonography } \\
{ }^{*} \text { statistically significant } \\
{ }^{1} \text { group } 1 \text { vs. group } 2,{ }^{2} \text { group } 1 \text { vs. group } 3,{ }^{3} \mathrm{~g}\end{array}$ & s. group $4,{ }^{4}$ gro & 35 & 政 & group 4 & \\
\hline
\end{tabular}

- Table 2 The $\beta$-hCG levels in all four groups on Day 0, Day 4, and Day 7.

\begin{tabular}{|c|c|c|c|c|c|}
\hline$\beta$-hCG & $\begin{array}{l}\text { Group } 1 \\
\text { Expectant management } \\
(\mathrm{n}=\mathbf{2 4 )}\end{array}$ & $\begin{array}{l}\text { Group } 2 \\
\text { Single dose methotrexate } \\
(n=144)\end{array}$ & $\begin{array}{l}\text { Group } 3 \\
\text { Multiple dose } \\
\text { methotrexate }(n=25)\end{array}$ & $\begin{array}{l}\text { Group } 4 \\
\text { Surgical intervention } \\
(n=40)\end{array}$ & p-value \\
\hline Day 0 & $1160.00 \pm 289.60^{1,2,3}$ & $1667.43 \pm 677.19^{1,4,5}$ & $2356.20 \pm 675.68^{2,4,6}$ & $4469.13 \pm 1194.00^{3,5,6}$ & $<0.001^{*}$ \\
\hline Day 4 & $756.25 \pm 177.33^{1,2}$ & $1445.16 \pm 630.61^{1,4}$ & $2024.00 \pm 620.56^{2,4}$ & - & $<0.001^{*}$ \\
\hline Day 7 & $539.17 \pm 134.52^{1,2}$ & $1144.84 \pm 593.7^{1,4}$ & $1626.64 \pm 580.35^{2,4}$ & - & $<0.001^{*}$ \\
\hline
\end{tabular}


Day 4. Moreover, the probability of the requirement for an additional dose of MTX was $1.64(95 \% \mathrm{Cl} 1.25-2.16$; $\mathrm{p}<0.001)$ times greater in patients who had $\mathrm{a}<15 \%$ decrease in $\beta$-hCG levels from Day 4 to Day 7 in comparison to those who had a $>15 \%$ decrease from Day 4 to Day 7.

Serum $\beta$-hCG concentrations were decreased on Day 4 in comparison to Day 0 in $76.39 \%$ of the patients who received a single dose of MTX and in $32.0 \%$ of patients who received two or more doses of MTX. The positive predictive value (93.22\%), the negative predictive value (33.33\%), sensitivity (76.39\%), and specificity $(68.0 \%)$ were calculated ( $\triangleright$ Table 4$)$. However, the $\beta$-hCG concentrations increased on Day 7 in comparison to Day 4 in $12.0 \%$ of the patients who received two or more doses of MTX and in $16.67 \%$ of the patients who received a single dose of MTX (positive predictive value: $84.51 \%$; negative predictive value: $11.11 \%$; sensitivity: $83.33 \%$; specificity: $12.0 \%$ ) (• Table 5).

The surgical procedures and hospital stay duration for patients with EP that underwent surgical treatment are summarized in - Table 6. In terms of surgical procedures, there was no difference between the laparatomy and laparoscopy groups

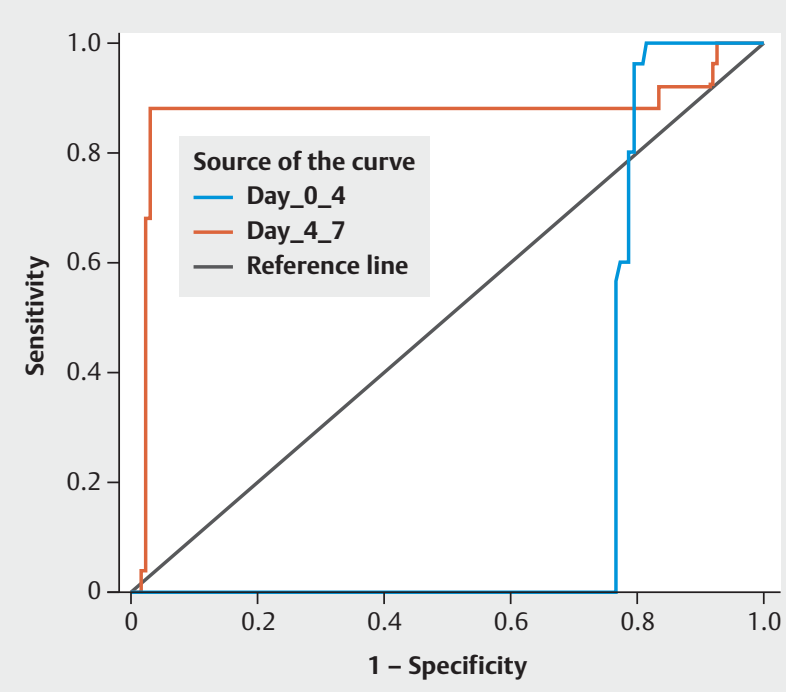

- Fig. 1 ROC curve for changes in the $\beta$-hCG level between Days 0-4 and Days 4-7 for an additional MTX dose.

- Table 3 Changes in the $\beta$-hCG values in all four groups from Day 0 to Day 4 and from Day 4 to Day 7 after methotrexate administration.

\begin{tabular}{|l|l|l|l|}
\hline & $\begin{array}{l}\text { Group 1 } \\
\text { Expectant management } \\
(\mathbf{n = 2 4 )}\end{array}$ & $\begin{array}{l}\text { Group 2 } \\
\text { Single dose methotrexate } \\
(\mathbf{n = 1 4 4 )}\end{array}$ & $\begin{array}{l}\text { Group 3 } \\
\text { Multiple dose methotrexate } \\
\text { (n= 25) }\end{array}$ \\
\hline Day 4-0 & $403.75 \pm 132.28^{1,2}$ & $222.27 \pm 65.82^{1,3}$ & $332.20 \pm 76.75^{2,3}$ \\
\hline Day 7-4 & $217.08 \pm 61.37^{1,2}$ & $300.31 \pm 72.54^{1,3}$ & $397.35 \pm 81.04^{2,3}$ \\
\hline P-value & $<0.001^{*}$ & $<0.001^{*}$ & $0.006^{*}$ \\
\hline \\
\hline * statistically significant
\end{tabular}

- Table 4 Analysis of patients based on differences between the $\beta$-hCG levels from Day 0 to Day 4.

\begin{tabular}{|c|c|c|c|c|c|c|}
\hline & \multicolumn{2}{|c|}{ Single dose methotrexate $(n=144)$} & \multicolumn{2}{|c|}{ Multiple dose methotrexate $(n=25)$} & \multirow[t]{2}{*}{ Total } & \multirow[t]{2}{*}{ PPV } \\
\hline & $\mathbf{n}$ & $\%$ & $\mathbf{n}$ & $\%$ & & \\
\hline Negative value & 110 & 76.39 & 8 & 32.0 & 118 & $93.22 \%$ \\
\hline Positive value & 34 & 23.61 & 17 & 68.0 & 51 & NPV \\
\hline \multirow[t]{2}{*}{ Total } & 144 & 100 & 25 & 100 & 169 & $33.33 \%$ \\
\hline & \multicolumn{2}{|c|}{ Sensitivity: 76.39} & \multicolumn{2}{|c|}{ Specificity: 68.0} & & \\
\hline
\end{tabular}

- Table 5 Analysis of patients based on differences between the $\beta$-hCG levels from Day 4 to Day 7.

\begin{tabular}{|c|c|c|c|c|c|c|}
\hline & \multicolumn{2}{|c|}{ Single dose methotrexate $(n=144)$} & \multicolumn{2}{|c|}{ Multiple dose methotrexate $(n=25)$} & \multirow[t]{2}{*}{ Total } & \multirow[t]{2}{*}{ PPV } \\
\hline & n & $\%$ & $\mathbf{n}$ & $\%$ & & \\
\hline Negative value & 120 & 83.33 & 22 & 88.0 & 142 & $84.51 \%$ \\
\hline Positive value & 24 & 16.67 & 3 & 12.0 & 27 & NPV \\
\hline \multirow[t]{2}{*}{ Total } & 144 & 100 & 25 & 100 & 169 & $11.11 \%$ \\
\hline & \multicolumn{2}{|c|}{ Sensitivity: 83.33} & \multicolumn{2}{|c|}{ Specificity: 12.0} & & \\
\hline
\end{tabular}

PPV: positive predictive value, NPV: negative predictive value 
- Table 6 Surgical procedures and hospital stay duration in patients with ectopic pregnancy who underwent surgical treatment.

\begin{tabular}{|l|l|l|l|}
\hline & Laparoscopy $(\mathbf{n = 3 6 )}$ & Laparatomy (n=4) & p-value \\
\hline Salpingostomy (\%) & $25(69.4)$ & $1(25.0)$ & 0.133 \\
\hline Salpingectomy (\%) & $9(25.0)$ & $3(75.0)$ & \\
\hline Tubal abortion (\%) & $2(5.6)$ & - & $0.009^{*}$ \\
\hline Hospital stay (days) & $1.44 \pm 0.50$ & $2.75 \pm 0.50$ & \\
\hline * statistically significant & & & \\
\hline
\end{tabular}

$(p=0.133)$, but the duration of hospital stay was less in the laparoscopy group $(p=0.009)$.

While the number of days for resolution of the $\beta$-hCG levels in patients with EP was lowest in Group 4, which consisted of patients that underwent a surgical intervention (14.45 \pm 4.43 days), it was highest in Group 2, which consisted of patients treated with a single dose of MTX $(21.85 \pm 7.35$ days $)(p<0.001)$.

\section{Discussion}

The current study investigated the results of EP treatment. Its findings show that as the percentage of ectopic mass appearance, the presence of fetal cardiac activity, the diameter of the ectopic mass and the initial serum $\beta$-hCG levels increase, the rate of surgical intervention increases. Initial $\beta$-hCG values $<1500 \mathrm{mIU} / \mathrm{L}$ appear to benefit from expectant management, while $\beta$-hCG values 1500-2000 mIU/L appear to benefit from single-dose MTX therapy, and $\beta$-hCG values $>2000 \mathrm{mIU} / \mathrm{L}$ appear to benefit from multiple-dose MTX therapy. This study also found that patients with a decrease in the serum $\beta$-hCG levels $>18 \%$ between Day 0 and Day 4 were 0.78 times less likely to require additional doses of MTX, and patients with a serum $\beta$-hCG level decrease $<15 \%$ between Day 4 and day 7 were 1.64 times more likely to require additional doses of MTX.

EP treatment depends on a patient's hemodynamic stability, compliance with long-term follow-up, $\beta$-hCG levels, fertility needs, the size of the EP and the presence of fetal cardiac activity [10].

Previous studies have reported that if the initial serum $\beta$-hCG values are $<1500 \mathrm{mIU} / \mathrm{L}$ in unruptured tubal EP cases, routine use of MTX is not recommended, and these cases may benefit from expectant management $[10,18,19]$. Pregnancies of unknown location with abnormal beta-human chorionic gonadotropin trends are frequently treated as presumed ectopic pregnancies with methotrexate. Endometrial aspiration with Karman cannula may be useful to diagnose pregnancy location so it prevents women from exposure to MTX $[18,19]$. It has been reported that the spontaneous resolution rate was $21 \%$ in patients with initial serum $\beta$-hCG values $>1500 \mathrm{mIU} / \mathrm{L}$ and $15 \%$ in patients with initial serum $\beta$-hCG values $>2000 \mathrm{mIU} / \mathrm{L}[20,21]$. Our study found that expectant management patients (10.3\%) had initial serum $\beta$-hCG values $<1500 \mathrm{mIU} / \mathrm{L}$, which is lower than the rates reported in the literature because our clinic is a tertiary center. Patients with EP are usually referred to our clinic for medical treatment or surgical intervention.
MTX is a safe and effective treatment modality for patients with appropriate criteria for medical treatment (e.g., hemodynamic stability, fertility demand). The single-dose MTX protocol is the most commonly used method for selected patients with $E P$, and the success rate of this treatment has been reported in the literature to range between 52 and 94\% [22, 23]. In our study, the treatment success rate was $83.33 \%$. The success of singledose MTX therapy can be affected by the patient's serum $\beta$-hCG levels, positive fetal cardiac activity, the presence of a yolk sac, and the size of the ectopic mass [14]. It has been suggested in the literature that treatment success is correlated with serum $\beta$-hCG values, and different cut-off values, such as $1790 \mathrm{mIU} / \mathrm{L}$ and $2000 \mathrm{mIU} / \mathrm{L}$, have been reported [11, 14, 22, 24]. However, it has also been claimed that $\beta$-hCG levels do not affect the success of MTX treatment [25]. The American Society for Reproductive Medicine (ASRM) Guidelines also suggest that the single-dose MTX treatment regimen fails at high initial serum $\beta$-hCG levels, and this treatment regimen is preferred over relatively low initial serum $\beta$-hCG levels. In addition, hemodynamic unstability (signs of tubal rupture), severe abdominal or pelvic pain, regardless of the change in $\beta$-hCG levels, and a > 53\% increase in the $\beta$-hCG levels after administration of a second dose of MTX in a single-dose MTX regimen are accepted as a poor response to medical treatment [26]. We also observed that the success rate of single-dose MTX treatment decreased when the initial serum $\beta$-hCG values were $>2000 \mathrm{mIU} / \mathrm{L}$, which is consistent with the findings reported in the literature. Medical treatment was not successful in patients with positive fetal cardiac activity in MTX treatment groups. So, extrauterine pregnancies with positive heart action should not be treated with MTX.

In a prospective randomized trial [4] comparing the success of single-dose MTX treatment versus multiple-dose MTX in patients with unruptured EP, no difference was found between the two MTX treatment regimens; this result is similar to the findings reported in previous studies $[25,27]$. We suggest that single-dose MTX regimens should be preferred when the side effects of multiple-dose MTX are considered. We did not find any difference in treatment success between the two MTX regimens, which is in accordance with the results reported in the literature.

It has been suggested that changes in the $\beta$-hCG values at Day 4 and Day 7, which were used to measure MTX treatment success, extended the length of hospital stay, caused unnecessary anxiety in patients, and increased the cost of treatment, so it has recently been claimed that early changes in $\beta$-hCG values at Day 0 and Day 4 could predict treatment success, and some cut-off values have 
been reported. The $\beta$-hCG values reported in the literature are very different, ranging from a $9.08 \%$ decrease to a $22.0 \%$ decrease in $\beta$-hCG levels between Day 0 and Day 4 [13, 14, 28, 29]. Agostini et al. [28] stipulated that a $>20 \%$ decrease in the $\beta$-hCG levels might predict the success rate of treatment as a $97 \%$ positive predictive value. Ustunyurt et al. [13] proposed that a $>22 \%$ decrease in the $\beta$-hCG level might predict the treatment success rate. Yildirim et al. [14] claimed that a $>22 \%$ decrease in $\beta$-hCG values might predict the treatment success rate with $86.6 \%$ sensitivity. Bottin et al. [29] reported a $100 \%$ treatment success rate if the decrease in the $\beta$-hCG value is $>20 \%$. However, Dogan et al. [11] found that the decrease in $\beta$-hCG levels between Day 0 and Day 4 might not predict treatment success. We found that a $>18 \%$ decrease in the $\beta$-hCG values between Day 0 and Day 4 might predict the treatment success rate with a sensitivity of $76.39 \%$ and a positive predictive value of $93.22 \%$.

A study conducted by Atkinson et al. [30] reported that a decrease in the $\beta$-hCG values between Day 4 and Day 7 was better than a decrease in the $\beta$-hCG values between Day 0 and Day 4 in predicting the need for an additional dose of MTX. When we analyzed our study results, we found that a $>15 \%$ decrease in the $\beta$-hCG values between Day 4 and Day 7 might predict the treatment success rate with a sensitivity of $83.33 \%$ and a positive predictive value of $84.51 \%$.

The limitation of this study is its retrospective design, the strength of the article is that all EP treatment options were compared.

In conclusion, if the initial serum $\beta$-hCG values are $<1500 \mathrm{mIU} /$ $\mathrm{L}$, expectant management is the preferred course of treatment, without any medical or surgical intervention. However, if the initial serum $\beta$-hCG values are $>1500 \mathrm{mIU} / \mathrm{L}$, a single-dose MTX regimen should be the first option for medical treatment. Optimal treatment in EP should be based on the knowledge and skill of the physician as well as the patient's hemodynamic status and fertility request, and the choice of treatment should be determined by consulting with the patient. The changes in $\beta$-hCG values at Day 0 and Day 4 after MTX administration can be considered to be criteria upon which to base the treatment; however, prospective randomized studies involving a larger series are needed to substantiate this claim and elucidate this issue.

Financial Support: None

Presented at a meeting: The abstract was presented as a poster presentation at ESGE 26th Annual Congress, 18th - 21st October 2017, Antalya Turkey.

\section{Conflict of Interest}

The authors declare that they have no conflict of interest.

\section{References}

[1] Centers for Disease Control (CDC). Ectopic pregnancy-United States, 1988-1989. MMWR Morb Mortal Wkly Rep 1992; 41: 591-594

[2] Farquhar CM. Ectopic pregnancy. Lancet 2005; 366: 583-591

[3] Buckley RG, King KJ, Disney JD et al. History and physical examination to estimate the risk of ectopic pregnancy: validation of a clinical prediction model. Ann Emerg Med 1999; 34: 589-594
[4] Guvendag Guven ES, Dilbaz S, Dilbaz B et al. Comparison of single and multiple dose methotrexate therapy for unruptured tubal ectopic pregnancy: a prospective randomized study. Acta Obstet Gynecol Scand 2010; 89: 889-895

[5] Fylstra DL. Tubal pregnancy: a review of current diagnosis and treatment. Obstet Gynecol Surv 1998; 53: 320-328

[6] Dart RG, Kaplan B, Varaklis K. Predictive value of history and physical examination in patients with suspected ectopic pregnancy. Ann Emerg Med 1999; 33: 283-290

[7] Mol BW, Hajenius PJ, Engelsbel S et al. Serum human chorionic gonadotropin measurement in the diagnosis of ectopic pregnancy when transvaginal sonography is inconclusive. Fertil Steril 1998; 70: 972-981

[8] Lipscomb GH, Givens VM, Meyer NL et al. Comparison of multidose and single-dose methotrexate protocols for the treatment of ectopic pregnancy. Am J Obstet Gynecol 2005; 192: 1844-1847

[9] Dorfman SF, Grimes DA, Gates W et al. Ectopic pregnancy mortality, United States 1979-1980: clinical aspects. Obstet Gynecol 1984; 64: 386-389

[10] Jurkovic D, Memtsa M, Sawyer E et al. Single-dose systemic methotrexate vs expectant management for treatment of tubal ectopic pregnancy: a placebo-controlled randomized trial. Ultrasound Obstet Gynecol 2017; 49: 171-176

[11] Dogan A, Gulhan I, Uyar I et al. Methotrexate treatment in progressive tubal ectopic pregnancies and hCG-related clinicosurgical implications. Kaohsiung J Med Sci 2016; 32: 317-322

[12] Tanaka T, Hayashi H, Kutsuzawa T et al. Treatment of interstitial ectopic pregnancy with methotrexate: report of a successful case. Fertil Steril 1982; 37: 851-852

[13] Ustunyurt E, Duran M, Coskun E et al. Role of initial and day 4 human chorionic gonadotropin levels in predicting the outcome of single-dose methotrexate treatment in women with tubal ectopic pregnancy. Arch Gynecol Obstet 2013; 288: 1149-1152

[14] Yıldırım A, Cırık DA, Altay M et al. Early prediction for the requirement of second or third dose methotrexate in women with ectopic pregnancy, treated with single-dose regimen. Arch Gynecol Obstet 2015; 291: 1327-1332

[15] Barnhart KT, Gosman G, Ashby R et al. The medical management of ectopic pregnancy: a meta-analysis comparing 'single dose' and 'multidose' regimens. Obstet Gynecol 2003; 101: 778-784

[16] Alleyassin A, Khademi A, Aghahosseini M et al. Comparison of success rates in the medical management of ectopic pregnancy with single-dose and multiple-dose administration of methotrexate: a prospective, randomized clinical trial. Fertil Steril 2006; 85: 1661-1666

[17] Lipscomb GH, Bran D, McCord ML et al. Analysis of three hundred fifteen ectopic pregnancies treated with single-dose methotrexate. Am J Obstet Gynecol 1998; 178: 1354-1358

[18] Levin I, Tsafrir Z, Sa'ar N et al. "Watchful waiting" in ectopic pregnancies: a balance between reduced success rates and less methotrexate. Fertil Steril 2011; 95: 1159-1160

[19] Kirk E, Van Calster B, Condous G et al. Ectopic pregnancy: using the hCG ratio to select women for expectant or medical management. Acta Obstet Gynecol Scand 2011; 90: 264-272

[20] Elson J, Tailor A, Banerjee $S$ et al. Expectant management of tubal ectopic pregnancy: prediction of successful outcome using decision tree analysis. Ultrasound Obstet Gynecol 2004; 23: 552-556

[21] Korhonen J, Stenman UH, Ylostalo P. Serum human chorionic gonadotrophin dynamics during spontaneous resolution of ectopic pregnancy. Fertil Steril 1994; 61: 632-636

[22] Sagiv R, Debby A, Feit $\mathrm{H}$ et al. The optimal cutoff serum level of human chorionic gonadotropin for efficacy of methotrexate treatment in women with extrauterine pregnancy. Int J Gynaecol Obstet 2012; 116: 101104 
[23] Gamzu R, Almog B, Levin Y et al. Efficacy of methotrexate treatment in extrauterine pregnancies defined by stable or increasing human chorionic gonadotropin concentrations. Fertil Steril 2002; 77: 761-765

[24] Nowak-Markwitz E, Michalak M, Olejnik M et al. Cutoff value of human chorionic gonadotropin in relation to the number of methotrexate cycles in the successful treatment of ectopic pregnancy. Fertil Steril 2009; 92: 1203-1207

[25] Natale A, Busacca M, Candiani M et al. Human chorionic gonadotropin patterns after a single dose of methotrexate for ectopic pregnancy. Eur J Obstet Gynecol Reprod Biol 2002; 100: 227-230

[26] Practice Committee of American Society for Reproductive Medicine. Medical treatment of ectopic pregnancy: a committee opinion. Fertil Steril 2013; 100: 638-644
[27] Potter MB, Lepine LA, Jamieson D]. Predictors of success with methotrexate treatment of tubal ectopic pregnancy at Grady Memorial Hospital. Am J Obstet Gynecol 2003; 188: 1192-1194

[28] Agostini A, Blanc K, Ronda I et al. Prognostic value of human chorionic gonadotropin changes after methotrexate injection for ectopic pregnancy. Fertil Steril 2007; 88: 504-506

[29] Bottin P, Gnisci A, Crochet P et al. [Prognostic value of early hCG changes after methotrexate injection for ectopic pregnancy]. Gynecol Obstet Fertil 2014; 42: 3-7

[30] Atkinson M, Gupta S, Mcgee T. BhCG monitoring after single-dose methotrexate treatment of tubal ectopic pregnancy: is the Day 4 BhCG necessary? A retrospective cohort study. Aust N Z J Obstet Gynaecol 2014; 54: $475-479$ 